\title{
Comparative study of fibrin and chemical synthetic sealant on dural regeneration and brain damage
}

\author{
Laboratory investigation
}

\author{
Kiyoshi Ito, M.D., ${ }^{1}$ Tetsuyoshi Horiuchi, M.D., Ph.D., ${ }^{1}$ Kiyomitsu Oyanagi, M.D., Ph.D., ${ }^{2}$ \\ Tetsuo Nomiyama, M.D., Ph.D., ${ }^{3}$ and Kazuhiro Hongo, M.D., Ph.D. ${ }^{1}$ \\ ${ }^{1}$ Department of Neurosurgery, ${ }^{2}$ Division of Neuropathology, Department of Brain Disease Research, \\ and ${ }^{3}$ Department of Preventive Medicine and Public Health, Shinshu University School of Medicine, \\ Matsumoto, Japan
}

\begin{abstract}
Object. Several materials, such as polyethylene glycol (PEG) hydrogel and fibrin glue, have been used to seal dural incisions after brain and spinal surgeries. Although the use of PEG sealant is gaining popularity, it can be associated with postoperative cerebrospinal fluid leakage and infection. However, the reasons for this association are currently unknown. The present study aimed to investigate the effects of PEG sealant and fibrin glue on wound healing and brain damage in vivo.

Methods. Oval-shaped bone defects and dural defects were created bilaterally over the parietal lobes of 22 Japanese white rabbits. The dural defects were covered with $0.5 \mathrm{ml}$ of fibrin glue on one side and $0.5 \mathrm{ml}$ of PEG sealant on the other side. Dural regeneration and brain damage were investigated in each harvested brain and dura mater using light microscopy.

Results. Dural regeneration was more effective in the presence of fibrin glue than it was with PEG sealant $(\mathrm{p}$ $=0.014)$. Of the 22 rabbits, 11 showed thick (Grades ++ and +++ ) dural regeneration by 28 days postsurgery in the hemisphere where fibrin glue was used, whereas Grade +++ dural regeneration was not observed in the PEG hydrogel hemisphere, and only 4 rabbits showed Grade ++ regeneration. Abscess and granulation formation also tended to be more severe when PEG hydrogel sealant was used. No Grade ++ granulation/abscess formation was observed with fibrin glue, and Grade + was only observed in 13 of 22 rabbits. Conversely, with PEG hydrogel sealant, only 2 rabbits did not show granulation/abscess formation, and Grade,+++ , and +++ granulation/abscess formation was observed in 8,7 , and 5 rabbits, respectively. The extent of cortical damage was significantly greater in rabbits with abscesses and granulations, compared with rabbits without these lesions $(p=0.007)$.

Conclusions. Dural regeneration tended to occur more rapidly with fibrin glue, whereas granulation was more likely with PEG hydrogel sealant, which led to postoperative complications. Histological analysis indicated that PEG hydrogel sealant inhibited the normal tissue healing process and that outcomes were improved by the use of fibrin glue.

(http://thejns.org/doi/abs/10.3171/2013.8.SPINE12998)
\end{abstract}

$\begin{array}{llll}\text { KEY WORDS } & \bullet & \text { chemical synthetic sealant } \bullet \text { dural regeneration } \bullet & \text { fibrin glue } \\ \text { granulation } & \bullet & \text { polyethylene glycol hydrogel sealant } \bullet \text { wound healing } & \text { rabbit }\end{array}$

$\mathrm{C}$ EREBROSPINAL fluid leakage sometimes occurs after brain and spinal surgery, and its prevention is important for successful recovery. Cerebrospinal fluid leakage can lead to adverse events such as postoperative infection and pseudomeningocele formation. ${ }^{8}$ Several different materials can be used as sealants during surgery to prevent postoperative CSF leakage.

Fibrin glue, a formulation used to create a fibrin clot, $, 112,19$ is widely used during neurosurgical procedures for this purpose. It can be used for the repair of dural tears and bronchial fistulas and to achieve intraoperative hemostasis. ${ }^{5}$ Recently, polyethylene glycol (PEG) hydrogel

Abbreviation used in this paper: $\mathrm{PEG}=$ polyethylene glycol. sealant has been introduced to the field of neurosurgery to achieve a watertight dural closure. .,, $14-16^{2}$ This hydrogel sealant system can also be used to seal dural defects. Polyethylene glycol hydrogel sealant is a chemical synthetic sealant formed by mixing PEG ester solution and trilysine amine solution. When mixed together, these precursors cross-link to form the hydrogel sealant. After application, the hydrogel gradually breaks down into water-soluble molecules that are absorbed and cleared through the kidneys. This process takes approximately $4-8$ weeks, allowing sufficient time for healing to occur.

This article contains some figures that are displayed in color online but in black-and-white in the print edition. 
Although the use of PEG hydrogel sealant during neurosurgical procedures is gaining popularity, we have occasionally encountered postoperative CSF leakage and infection after its use. Moreover, there are no previous histopathological studies comparing wound healing and effects on the brain and spinal cord following the use of fibrin glue and chemical synthetic sealant. Our aim was to investigate whether the use of fibrin glue or PEG hydrogel sealant resulted in different effects on wound healing and brain damage studied histopathologically in vivo.

\section{Methods \\ Study Design and Surgical Procedures}

This study was completed in compliance with experimental approval from the Division of Laboratory Animal Research, Department of Research for Human and Environmental Sciences, Shinshu University School of Medicine. Surgical procedures were performed in 22 female Japanese white rabbits $(3.0-3.5 \mathrm{~kg})$ using routine sterile techniques. Antibiotics were administered before skin incision and were continued for 3 days after surgery. After general anesthesia was induced, an oval-shaped bone window was made over both parietal lobes, and dural defects (5 $\mathrm{mm}$ in diameter) were created. The dural defects were then covered with $0.5 \mathrm{ml}$ of fibrin glue (Beriplast P, CSL Behring) on one side and $0.5 \mathrm{ml}$ of PEG hydrogel sealant (DuraSeal, Confluent Surgical) on the other side (Fig. 1); the wound was sutured with 4-0 Prolene polypropylene sutures (Ethicon, Inc.). In addition to skin suturing, the tissue adhesive Histoacryl (B. Braun Medical, Inc.) was used as an antibacterial barrier. Elizabethan collars were also used to protect the wound. All animals were examined postoperatively, beginning from the day after surgery and continuing for up to 4 weeks. Five or 7 rabbits were killed at each of the following time points: 7, 14, 21, and 28 days after surgery. The rabbits underwent perfusion fixation using $1 \%$ heparin in $0.1 \mathrm{M}$ phosphate-buffered saline, then $4 \%$ paraformaldehyde in $0.1 \mathrm{M}$ phosphate-buffered saline, and the brain and dura mater were harvested from each animal for histological analyses. Harvested tissues were embedded in paraffin, cut, and stained with $\mathrm{H} \& \mathrm{E}$, Masson's trichrome, and Luxol fast blue. The light microscopy findings of each harvested brain and dura mater were investigated by researchers blinded to which sealant had been used.

To compare neural tissue, wound healing, and dural regeneration after the use of fibrin glue and PEG sealant, microscopic investigation of each section was carried out using special reference to the following points: 1) extent of dural regeneration; 2) extent of granulation/abscess formation in the cerebral cortex; and 3) extent of cortical brain damage. To evaluate the extent of dural regeneration, the thickness of the dura mater was measured. Dural thickness was determined according to the following scale: Grade -, only collagen fiber formation; Grade +, irregular fibrous formation; Grade ++, dura formed, but less than $50 \mu \mathrm{m}$ thick; and Grade +++, dura of more than $50 \mu \mathrm{m}$ formed (Fig. 2). The degree of granulation/abscess formation was divided into 4 grades according to the thickness:

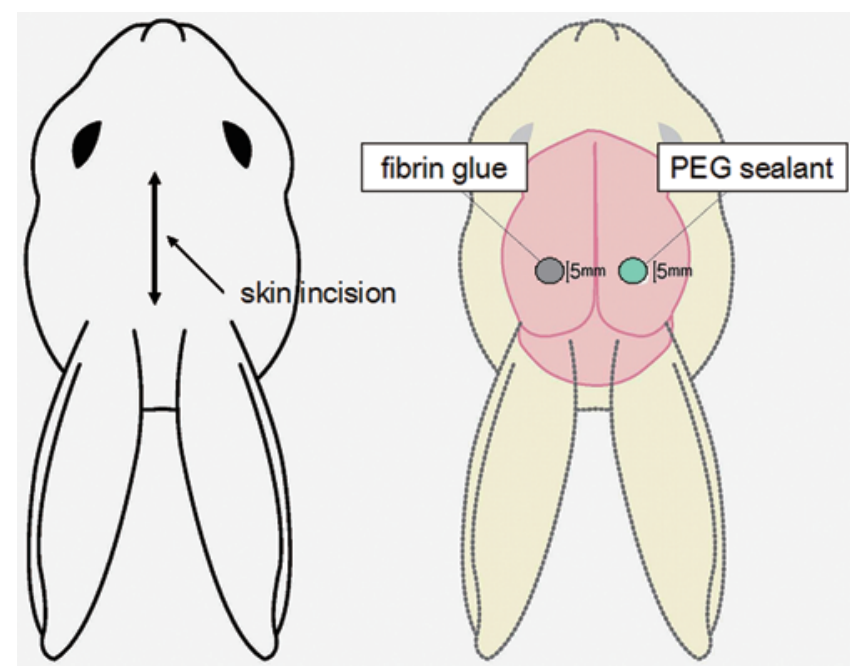

FIg. 1. Schematic drawings of the Japanese white rabbits with an oval-shaped bone flap and dural defects created over both parietal lobes. After skin incision and bur hole craniotomy, the dural defects were covered with fibrin glue on one side and PEG hydrogel sealant on the other. Copyright Kiyoshi Ito. Published with permission.

Grade -, no granulation/abscess formation; Grade +, less than $1 \mathrm{~mm}$; Grade ++, 1-5 mm; and Grade +++, more than $5 \mathrm{~mm}$ (Fig. 3). The extent of cortical brain damage was assessed and graded according to the thickness of the injured cortex: Grade -, no damage; Grade +, one-third of the cortical layer; Grade ++, two-thirds of the cortical layer; and Grade +++, all cortical layers damaged (Fig. 4).

\section{Statistical Analysis}

Two-group comparisons were performed using the chi-square or Fisher's exact test, and statistical calculations were performed using IBM SPSS Statistics software (version 20, IBM, Inc.); p values less than 0.05 were considered significant.

\section{Results}

The findings in each rabbit are summarized in Table 1.

\section{Dural Regeneration}

Dural regeneration was more rapid with fibrin glue, with Grade ++ and +++ regeneration observed from the 7th postoperative day, while these were not observed until the 14th postoperative day with PEG hydrogel sealant.

Of the 22 rabbits, 11 showed thick (Grade ++ and +++ ) dural regeneration by 28 days postsurgery in the hemisphere where fibrin glue was used, whereas Grade +++ dural regeneration was not observed in the PEG hydrogel hemisphere, and only 4 rabbits showed Grade ++ regeneration. In 2 rabbits, no dural regeneration was observed where fibrin glue was used. One of these was examined 1 week postsurgery, and the other was examined 3 weeks postsurgery. For PEG hydrogel sealant, 2 animals at 1 and 2 weeks and 3 animals at 3 and 4 weeks (10 rabbits in total) did not exhibit any dural regeneration. For 3 of 5 rabbits examined on the 28th postoperative day, when 
K. Ito et al.
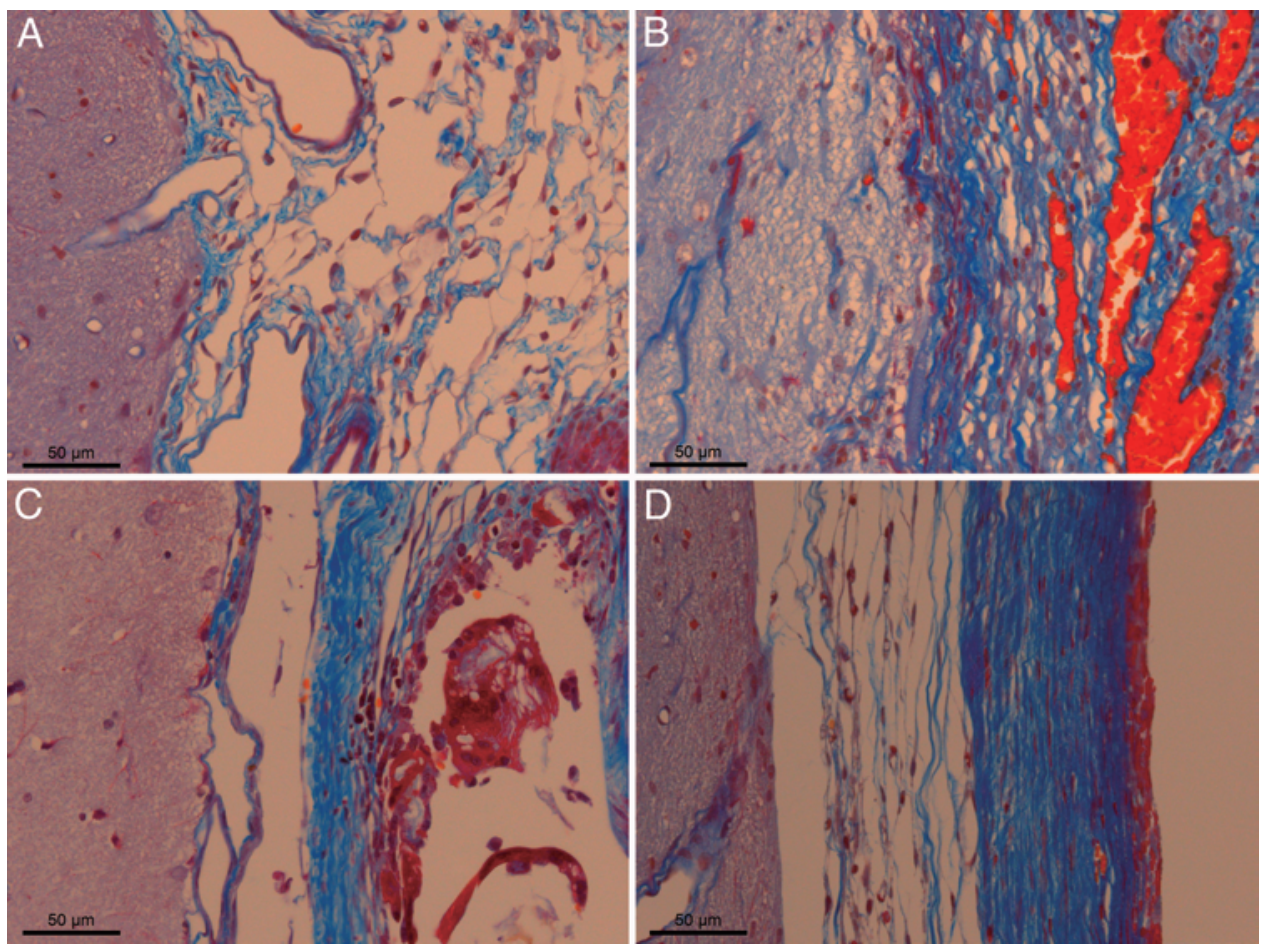

FIG. 2. Photomicrograph. Dural thickness was determined according to the following scale: Grade -, only collagen fiber formation (A); Grade +, irregular fibrous formation (B); Grade ++, less than $50 \mu \mathrm{m}$ (C); and Grade +++, more than $50 \mu \mathrm{m}$ (D). Luxol fast blue, original magnification $\times 480$.

hydrolysis of the PEG hydrogel sealant was likely to have started, dural regeneration was not confirmed. Overall, dural regeneration was significantly improved $(\mathrm{p}=0.014)$ when fibrin glue was used, compared with PEG hydrogel sealant (Fig. 5).

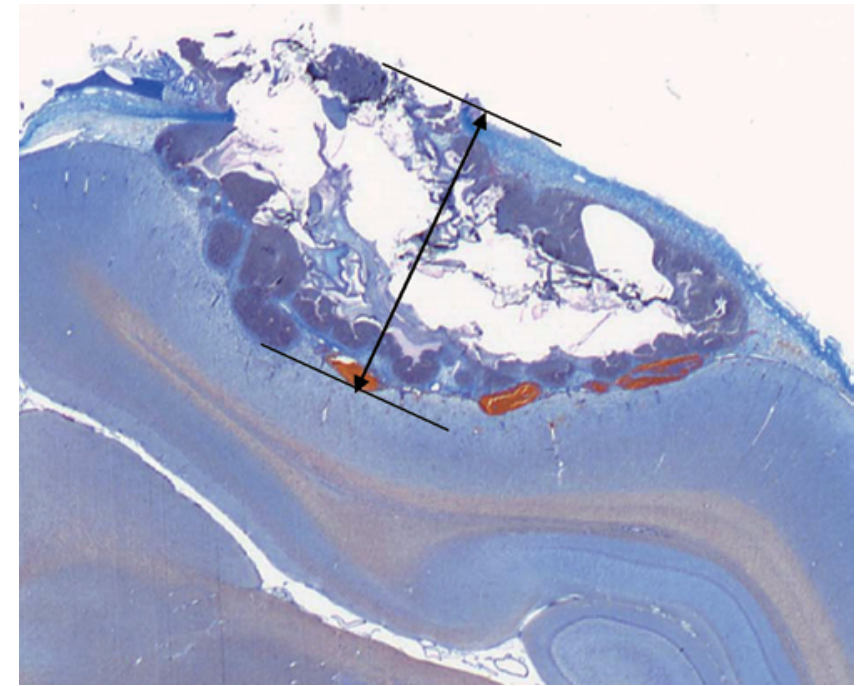

Fig. 3. Photomicrograph. The degree of the granuloma was categorized into 4 grades according to the thickness: Grade -, no granuloma formation; Grade +, less than $1 \mathrm{~mm}$; Grade ++, from 1 to $5 \mathrm{~mm}$; Grade +++ , more than $5 \mathrm{~mm}$. The double headed arrow indicates the thickness of the granuloma. The parallel lines indicate the borders of the granuIoma. Luxol fast blue, original magnification $\times 200$.

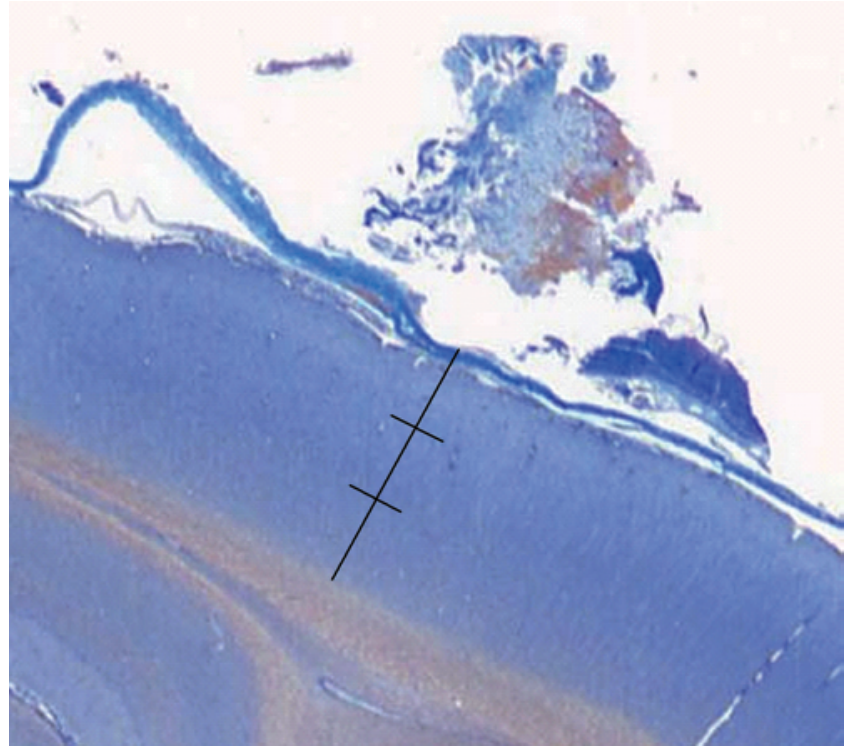

FIG. 4. Photomicrograph showing the extent of cortical brain damage was assessed and graded according to the thickness of the injured cortex: Grade -, no damage; Grade +, one-third of the cortical layer damaged; Grade ++, two-thirds of the cortical layer damaged; and Grade +++, all cortical layers damaged. The parallel lines indicate the different layers of the gray matter. The large line indicates the cortical layer of the brain. Luxol fast blue, original magnification $\times 200$. 
Postoperative reaction to sealant materials

TABLE 1: The findings in fibrin glue and PEG sealant cases*

\begin{tabular}{|c|c|c|c|c|c|c|}
\hline \multirow[b]{2}{*}{ Survival Time \& Animal No. } & \multicolumn{2}{|c|}{ Dural Regeneration } & \multicolumn{2}{|c|}{ Granulation } & \multicolumn{2}{|c|}{ Brain Damage } \\
\hline & Fibrin Glue & PEG Sealant & Fibrin Glue & PEG Sealant & Fibrin Glue & PEG Sealant \\
\hline \multicolumn{7}{|l|}{1 wk } \\
\hline 1 & ++ & - & + & ++ & + & ++ \\
\hline 2 & + & + & + & + & ++ & ++ \\
\hline 3 & ++ & + & + & + & - & ++ \\
\hline 4 & +++ & - & + & +++ & - & + \\
\hline 5 & - & + & - & - & ++ & - \\
\hline \multicolumn{7}{|l|}{2 wks } \\
\hline 6 & + & ++ & + & + & + & - \\
\hline 7 & ++ & - & - & ++ & ++ & + \\
\hline 8 & + & ++ & - & + & - & - \\
\hline 9 & +++ & + & - & ++ & - & + \\
\hline 10 & + & - & + & ++ & - & ++ \\
\hline \multicolumn{7}{|l|}{3 wks } \\
\hline 11 & - & - & +++ & +++ & +++ & +++ \\
\hline 12 & +++ & - & - & +++ & + & +++ \\
\hline 13 & ++ & + & - & +++ & + & + \\
\hline 14 & ++ & - & + & ++ & + & ++ \\
\hline 15 & + & + & + & + & ++ & - \\
\hline 16 & ++ & ++ & + & + & - & - \\
\hline 17 & + & + & + & + & - & - \\
\hline \multicolumn{7}{|l|}{4 wks } \\
\hline 18 & +++ & - & - & + & + & + \\
\hline 19 & + & - & + & ++ & - & ++ \\
\hline 20 & + & ++ & + & ++ & ++ & ++ \\
\hline 21 & ++ & + & + & +++ & ++ & +++ \\
\hline 22 & + & - & - & - & - & - \\
\hline
\end{tabular}

* See text of Methods for an explanation of the grading system used in this table.

Granulation and Abscess Formation in the Cerebral Cortex

Granulation tissue and abscess formation were significantly more severe with PEG hydrogel sealant (Fig. 6). No Grade ++ granulation/abscess formation was observed with fibrin glue, and Grade + was observed in 13 of 22 rabbits. Only 1 rabbit, examined in the 3rd week, showed Grade +++, which was formed in the 3rd week due to infection. Conversely, with PEG hydrogel sealant, only 2 rabbits did not show granulation/abscess formation, and Grade,+++ , and +++ granulation/abscess formation

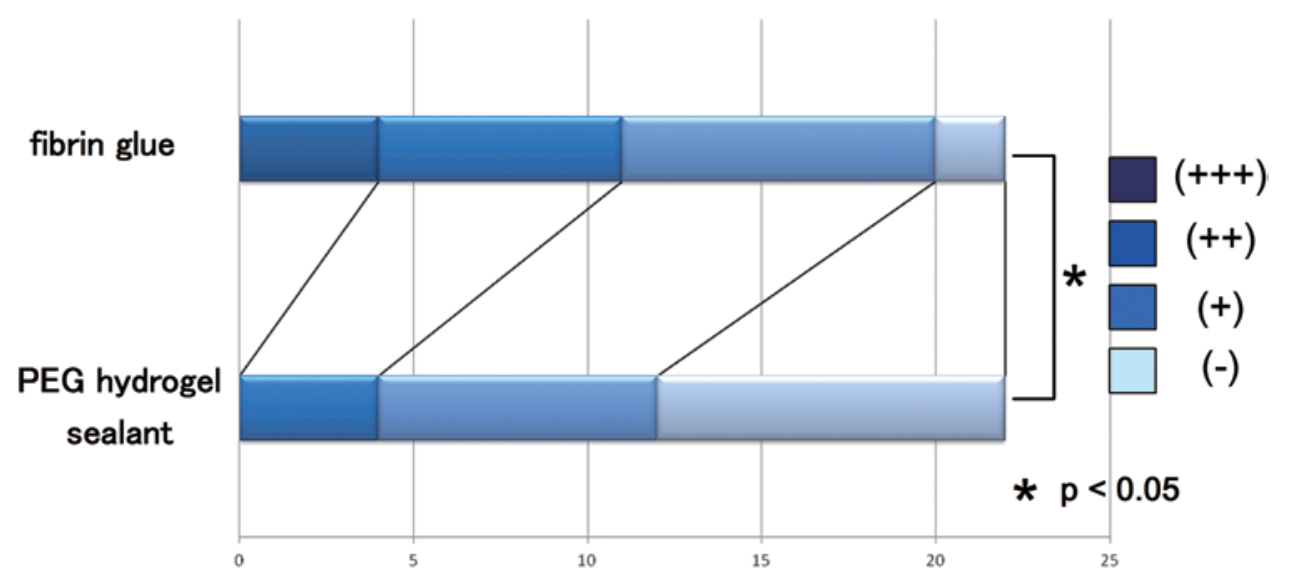

FIG. 5. Graph showing the extent of dural regeneration in the presence of fibrin glue and PEG hydrogel. There was a statistically significant difference using Fisher's exact test $(p=0.014)$. The numbers on the $x$ axis indicate the number of animals. 


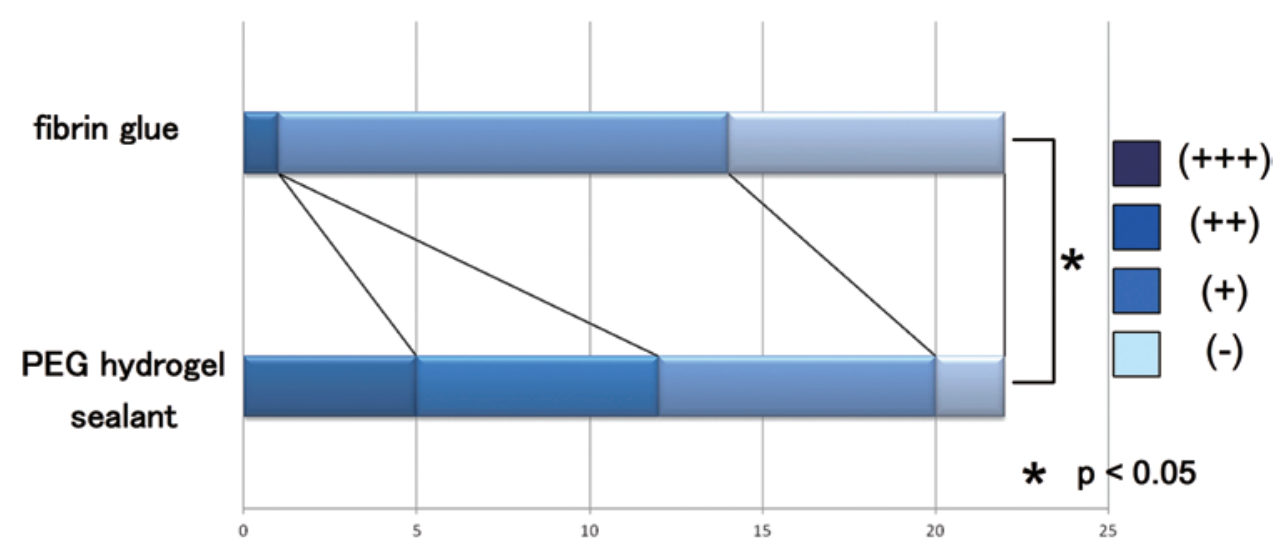

FIG. 6. Graph showing the extent of cortical granulation/abscess formation in the presence of fibrin glue and PEG hydrogel. The use of fibrin glue was associated with significantly less Grade ++ or +++ granulation/abscess, compared with PEG sealant.

was observed in 8, 7, and 5 rabbits, respectively. Grade +++ granulation/abscess formation was also due to acute infection rather than accumulation of inflammatory cells owing to the surgical procedure. Such severe granulation (Grade +++ ) was observed from the 7th postoperative day. Overall, the use of fibrin glue resulted in significantly less Grade ++ or +++ granulation/abscess formation, demonstrating that these were more likely to occur when PEG hydrogel sealant was used.

\section{Cortical Brain Damage}

Cortical brain damage was thought to be caused mainly by compression of the granulation/abscess formed in a brain surface as shown in our histopathological specimen (Fig. 7). To investigate whether cortical damage occurred as a result of compression caused by granulation/ abscess formation on the brain surface, the influence of granulation and abscess formation on cortical brain damage was analyzed statistically. Figure 8 demonstrates that cortical damage was significantly more severe in rabbits with granulation/abscess tissue, compared with rabbits without granulation/abscess tissue $(\mathrm{p}=0.007)$.

In many cases, the PEG hydrogel sealant covered the granulation/abscess tissue from above like a cap (Fig. 9A). It contained massive infiltration of neutrophils with rare blood vessels (Fig. 9B and C). The high rigidity of the PEG hydrogel sealant prevented inflammatory cells from spreading outward, causing the granulation/abscess tissue to develop inward, toward the cerebral cortex. Thus, in addition to increasing the likelihood of granulation/abscess formation, cortical damage was also more likely with PEG hydrogel, because of increased brain compression.

\section{Discussion}

Cerebrospinal fluid leakage can occur after cerebral and intradural spinal surgery, because primary dural closure can sometimes be difficult. A recent study revealed that only $6 \%$ of conventional sutured closures in cranial and spinal procedures were watertight when tested using a Valsalva maneuver. ${ }^{12}$ Therefore, to avoid CSF leakage, meticulous primary dural closure with a sealing material is required.

One of these materials is fibrin glue, made up of fi- brinogen and thrombin, an enzyme that converts the fibrinogen into fibrin, which acts as a tissue adhesive. ${ }^{19}$ This glue can be used for repairing dural tears and bronchial fistulas and for achieving intraoperative hemostasis. Fibrin glue is reported to be a useful surgical tool for preventing postoperative subcutaneous fluid collection through dural sutures. For example, Shaffrey et al. reported that CSF leakage occurred postoperatively in only $5 \%$ of 83 patients with the use of fibrin glue. ${ }^{19}$ Nagata et al. also reported that only 1 of 33 patients showed CSF leakage with the mesh-and-glue technique, which uses polyglycolic acid mesh and fibrin glue, indicating that this technique was more effective in preventing CSF leakage than fibrin glue alone. $^{12}$ The mesh-and-glue technique and laminoplastic laminotomy have proved effective in preventing postoperative CSF leakage in intradural spinal surgery. ${ }^{7,8}$ However, fibrin glue is used along with a synthetic substance such as aprotinin, fibrinogen, and thrombin to create a fibrin clot; therefore, the fibrin glue carries the risk of unknown viral transfer, or the patient may develop an anaphylactic reaction to aprotinin. $4,9,17,18$

Recently, a PEG hydrogel sealant was developed to achieve a watertight dural closure. ${ }^{15,16}$ A PEG hydrogel sealant eliminates the risk of viral transmission and reduces the risk of allergic reactions. The results of a prospective, randomized controlled trial of PEG were reported in 2011. ${ }^{10}$ This report summarized data for PEG usage in 158 cases, and this material seemed to have high reliability.

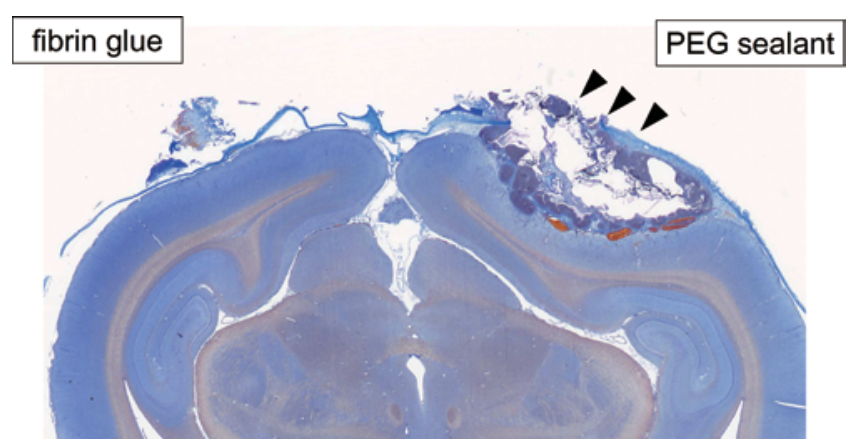

FIG. 7. Photomicrograph showing the granulation/abscess formation on the brain surface (arrowheads). Masson's trichrome, original magnification $\times 100$. 


\section{Postoperative reaction to sealant materials}

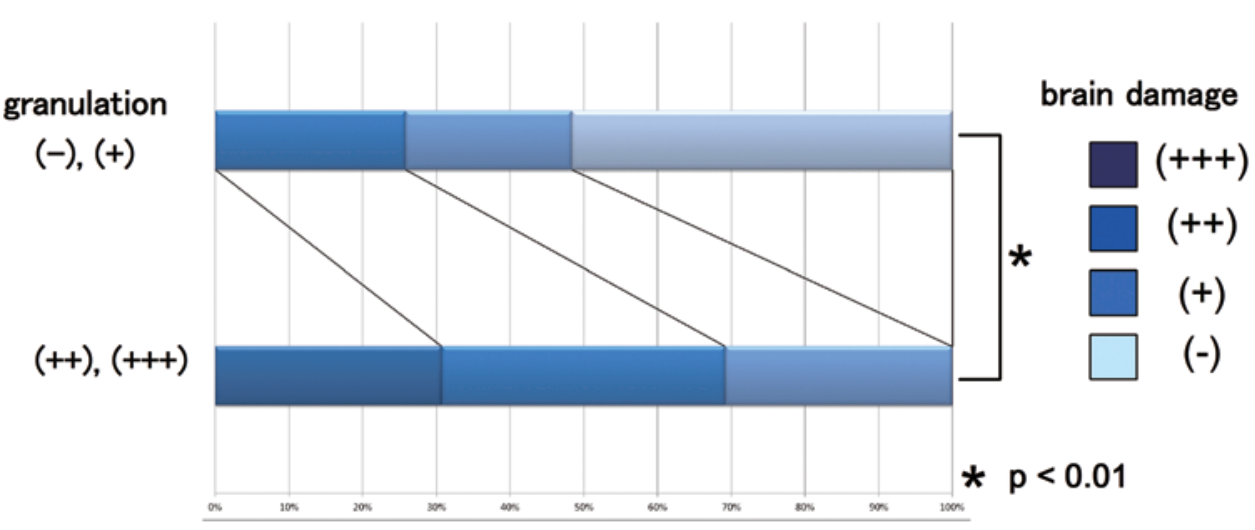

FIG. 8. Graph showing the relationship between granulation/abscess formation and cortical brain damage. Cortical damage was significantly more severe in rabbits with granulation/abscess tissue than in rabbits without granulation/abscess tissue using the Fisher's exact test $(p=0.007)$.

However, histopathological examinations were not carried out in that report. The present study aimed to evaluate histopathological outcomes to investigate biocompatibility. Little is known about the comparative histopathological effects of fibrin glue and PEG hydrogel sealant on dural regeneration and neural damage.

\section{Dural Regeneration}

Although CSF leakage represents an important postoperative complication in humans, the volume of rabbit
CSF is so low that it was difficult to quantify leakage during the present study. The efficacy of preventing CSF leakage could not be compared between the sealant materials. Therefore, the degree of dural regeneration was used as a proxy for this important outcome.

In the present study, dural regeneration was more effective when fibrin glue was used, compared with PEG hydrogel sealant. A thicker dura mater was formed in a shorter time with fibrin glue, with Grade ++ and +++ dural generation, indicating a strong structure comparable to

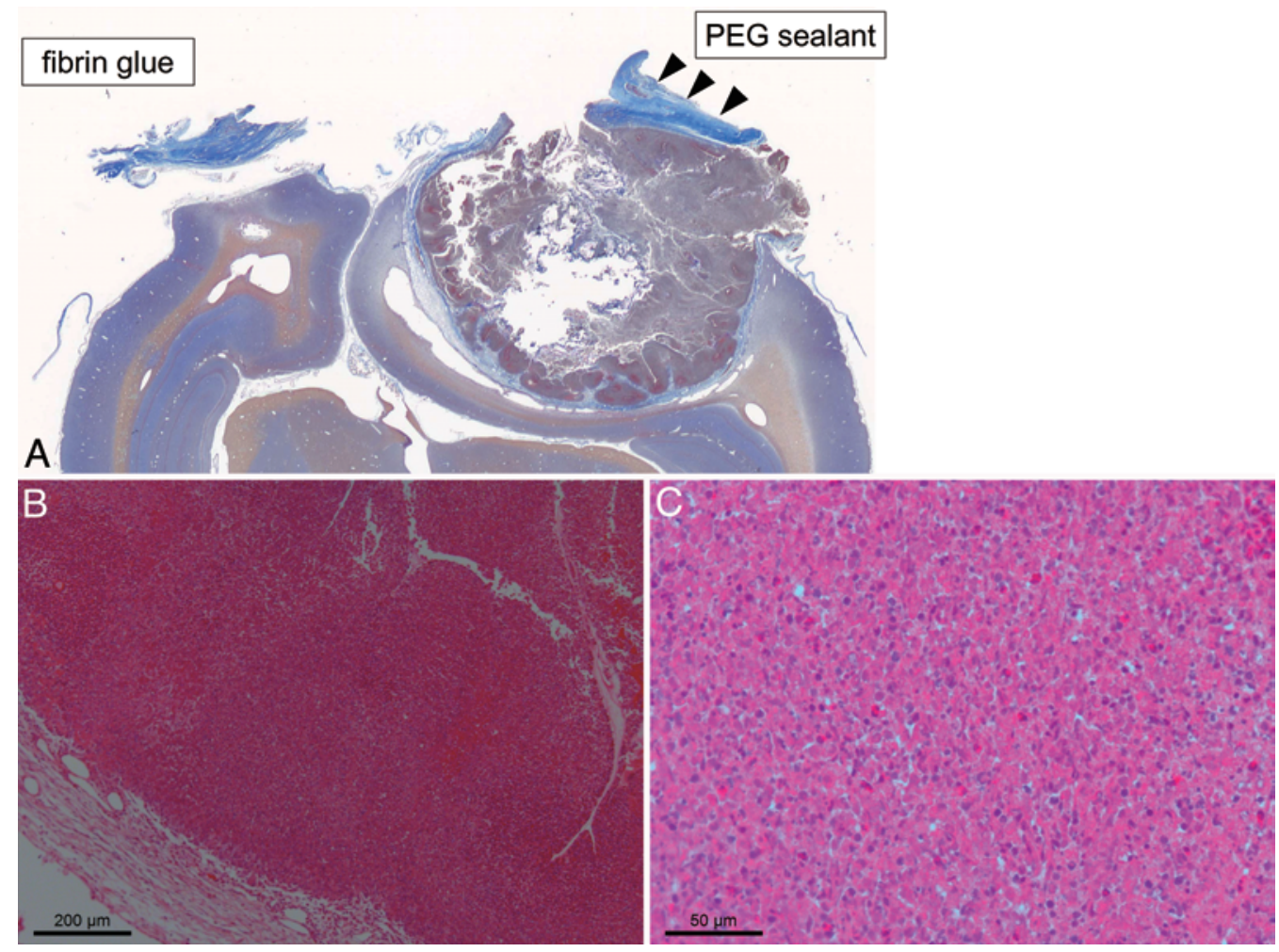

FIG. 9. Photomicrographs. A: An example of the severe granulation/abscess tissue formed in the bur hole covered with PEG sealant. In many cases, the PEG hydrogel sealant covered the granulation/abscess tissue from above like a cap (arrowheads). Luxol fast blue, original magnification $\times 100$. B and C: Severe granulation in tissue covered with the PEG hydrogel sealant can be seen at low magnification $\times 120(B)$ and high magnification $\times 480(C)$. Extensive neutrophil infiltration was occasionally observed, with rare blood vessels. $H \& E(B$ and $C)$. 
normal dura. Therefore, postoperative CSF leakage would be predicted to be reduced with fibrin glue. Moreover, some rabbits exhibited no dural regeneration on the side using PEG hydrogel sealant, even at 4 weeks after surgery when PEG hydrolysis generally begins. This indicated that CSF leakage could potentially occur, even at this late time point.

\section{Granulation/Abscess Formation in the Cerebral Cortex and Cortical Brain Damage}

The effects of PEG hydrogel sealant on wound healing were also examined. Granulation/abscess formed more readily in the vicinity of incisions sealed with PEG hydrogel than in those sealed with fibrin glue. Grade + granulation indicated the accumulation of inflammatory cells, such as granulocytes and macrophages, in response to the surgical procedure, rather than acute infection. Grade ++ or +++ granulation was thought to be due to acute infection, rather than inflammation caused by the surgical procedure, in our sample set. Because of this distinction, the degree of granulation/abscess or brain damage was divided into 2 subcategories (Fig. 8). Severe granulation/abscess was observed more frequently on the side sealed with PEG hydrogel sealant than on the fibrin glue side. The granulation/abscess tissue formation observed in the fibrin glue-treated incisions indicated ongoing biological repair, which was not observed to the same extent on the side sealed with PEG hydrogel..$^{1,5,6,10,18}$ No significant abscess formation was found in the fibrin glue-sealed incisions in this study. Adequate blood supply is very important for accelerating wound healing and preventing postoperative infection. The lack of blood supply or inflammatory cell infiltration into the artificial PEG hydrogel may have contributed to its poor performance in this respect. ${ }^{11,13}$ In addition, antibiotics administered to treat a patient may be rendered ineffective because of this reduced blood supply. Therefore, although a previous study found that PEG hydrogel sealant did not directly damage the brain parenchyma, ${ }^{14}$ the present study indicated that it may cause cortical damage indirectly via granuloma formation on the brain surface.

\section{Conclusions}

In this study, we compared the effects of fibrin sealant and a chemical synthetic sealant, PEG hydrogel, on postoperative dural regeneration and brain damage. Dural regeneration tended to occur more rapidly with fibrin glue, whereas negative outcomes (granulation/abscess formation) were more frequent with PEG hydrogel sealant. However, the efficacy of the 2 sealants in preventing CSF leakage remains to be studied. We propose that the artificial nature of PEG hydrogel sealant inhibited the normal tissue healing process. In contrast, the use of fibrin glue facilitated a more normal wound healing process, resulting in more effective dural regeneration.

\section{Acknowledgments}

We thank Ms. M. Asakawa; Dr. E. Suzuki; Division of Neuropathology, Department of Brain Disease Research, Shinshu Univer- sity School of Medicine; and Ms. M. Mari, Department of Preventive Medicine and Public Health, Shinshu University School of Medicine, for their technical support in this study.

\section{Disclosure}

This work was funded by CSL Behring Co. The authors report no conflict of interest concerning the materials or methods used in this study or the findings specified in this paper.

Author contributions to the study and manuscript preparation include the following. Conception and design: Ito. Acquisition of data: Ito, Oyanagi. Analysis and interpretation of data: Ito, Horiuchi, Oyanagi. Drafting the article: Ito. Critically revising the article: all authors. Reviewed submitted version of manuscript: all authors. Approved the final version of the manuscript on behalf of all authors: Ito. Statistical analysis: Ito, Nomiyama. Administrative/technical/ material support: Oyanagi. Study supervision: Hongo.

\section{References}

1. Barbolt TA, Odin M, Léger M, Kangas L: Pre-clinical subdural tissue reaction and absorption study of absorbable hemostatic devices. Neurol Res 23:537-542, 2001

2. Boogaarts JD, Grotenhuis JA, Bartels RH, Beems T: Use of a novel absorbable hydrogel for augmentation of dural repair: results of a preliminary clinical study. Neurosurgery 57 (1 Suppl):146-151, 2005

3. Cosgrove GR, Delashaw JB, Grotenhuis JA, Tew JM, Van Loveren H, Spetzler RF, et al: Safety and efficacy of a novel polyethylene glycol hydrogel sealant for watertight dural repair. J Neurosurg 106:52-58, 2007

4. Fergusson DA, Hébert PC, Mazer CD, Fremes S, MacAdams C, Murkin JM, et al: A comparison of aprotinin and lysine analogues in high-risk cardiac surgery. N Engl J Med 358:23192331, 2008

5. Ghulam Muhammad AK, Yoshimine T, Maruno M, Takemoto O, Hayakawa T: Topical application of fibrin adhesive in the rat brain: effects on different cellular elements of the wound. Neurol Res 19:84-88, 1997

6. Herrera O, Kawamura S, Yasui N, Yoshida Y: Histological changes in the rat common carotid artery induced by aneurysmal wrapping and coating materials. Neurol Med Chir (Tokyo) 39:134-140, 1999

7. Hida K, Yamaguchi S, Seki T, Yano S, Akino M, Terasaka S, et al: Nonsuture dural repair using polyglycolic acid mesh and fibrin glue: clinical application to spinal surgery. Surg Neurol 65:136-143, 2006

8. Ito K, Ishizaka S, Sasaki T, Miyahara T, Horiuchi T, Sakai K, et al: Safe and minimally invasive laminoplastic laminotomy using an ultrasonic bone curette for spinal surgery: technical note. Surg Neurol 72:470-475, 2009

9. Kanazawa R, Sato S, Iwamoto N, Teramoto A: Allergic reaction following arachnoid plasty with a fibrin sealant. Neurol Med Chir (Tokyo) 50:608-610, 2010

10. Kim KD, Wright NM: Polyethylene glycol hydrogel spinal sealant (DuraSeal Spinal Sealant) as an adjunct to sutured dural repair in the spine: results of a prospective, multicenter, randomized controlled study. Spine (Phila Pa 1976) 36:19061912, 2011

11. Louw JA: Spinal tuberculosis with neurological deficit. Treatment with anterior vascularised rib grafts, posterior osteotomies and fusion. J Bone Joint Surg Br 72:686-693, 1990

12. Nagata K, Kawamoto S, Sashida J, Abe T, Mukasa A, Imaizumi Y: Mesh-and-glue technique to prevent leakage of cerebrospinal fluid after implantation of expanded polytetrafluoroethylene dura substitute-technical note. Neurol Med Chir (Tokyo) 39:316-319, 1999

13. Nakamura H, Yamano Y, Seki M, Konishi S: Use of folded vas- 


\section{Postoperative reaction to sealant materials}

cularized rib graft in anterior fusion after treatment of thoracic and upper lumbar lesions. Technical note. J Neurosurg 94 (2 Suppl):323-327, 2001

14. Preul MC, Bichard WD, Spetzler RF: Toward optimal tissue sealants for neurosurgery: use of a novel hydrogel sealant in a canine durotomy repair model. Neurosurgery 53:1189-1199, 2003

15. Preul MC, Campbell PK, Bichard WD, Spetzler RF: Application of a hydrogel sealant improves watertight closures of duraplasty onlay grafts in a canine craniotomy model. J Neurosurg 107:642-650, 2007

16. Preul MC, Campbell PK, Garlick DS, Spetzler RF: Application of a new hydrogel dural sealant that reduces epidural adhesion formation: evaluation in a large animal laminectomy model. Laboratory investigation. J Neurosurg Spine 12:381-390, 2010

17. Sanal M, Doğruyol H, Gürpinar A, Yerci O: Does fibrin glue cause foreign body reactions? Eur J Pediatr Surg 2:285-286, 1992

18. Schievink WI, Georganos SA, Maya MM, Moser FG, Bladyka M: Anaphylactic reactions to fibrin sealant injection for spontaneous spinal CSF leaks. Neurology 70:885-887, 2008

19. Shaffrey CI, Spotnitz WD, Shaffrey ME, Jane JA: Neurosurgical applications of fibrin glue: augmentation of dural closure in 134 patients. Neurosurgery 26:207-210, 1990

Manuscript submitted October 30, 2012.

Accepted August 19, 2013.

Please include this information when citing this paper: published online September 27, 2013; DOI: 10.3171/2013.8.SPINE12998.

Address correspondence to: Kiyoshi Ito, M.D., Department of Neurosurgery, Shinshu University School of Medicine, 3-1-1 Asahi, Matsumoto 390-8621, Japan. email: kitoh@shinshu-u.ac.jp. 